\title{
A STATUS REPORT ON THE DEVELOPMENT OF A HIGH POWER UV AND IR FEL AT CEBAF
}

\author{
S. V. Bensona, J. Bisognanoa, C. Bohna, L. Cardmana, W. B. Colsonc, \\ D. Douglasa, H. F. Dyllaa, D. Engwallf, J. Fugitta, J. Goldstein'b, K. Jordana, D. Kehnea, \\ Z. Lid, H. Liua, L. Mermingaa, G. Neila, D. Neuffera, M. Shinna, \\ M. Wisemana, R. Wongc, and M. Xiee \\ a Continuous Electron Beam Accelerator FacilityNewport News, VA 23606 USA \\ bLos Alamos National Laboratory, Los Alamos, NM 87545 USA \\ cNaval Postgraduate School, Monterey, CA 93943 USA \\ d Stanford Linear Accelerator Center, Stanford, University, Stanford, CA 94305 USA \\ - Lawrence Berkeley Laboratory, Berkeley CA 94720 USA \\ Nuclear Physics Laboratory,Univ. of Ill. at Urbana-Champaign, Urbana, IL 61801 USA
}

Oral Presentation Tu2-3

Corresponding author:

Stephen Benson MS 16A

Continuous Electron Beam Accelerator Facility

Newport News, VA 23606 USA

Phone 1(804)249-5025

FAX 1(804)249-7352

email address felman@cebaf.gov

\section{Abstract}

Previously we presented a design for a kilowatt demonstration industrial UVFEL [1]. Progress has been made in resolving several design issues identified in that work. More exact simulations of the injector have resulted in a better estimate of the injector performance. A more compact lattice has been designed meeting the design requirements for the UV FEL, and a new design point has been studied which greatly increases the threshold for longitudinal instabilities. A stability analysis of the RF control system has found that only minor modifications from the existing CEBAF controls will be necessary to allow them to be used with a high current, energyrecovery accelerator. Designs for the optical cavity length and figure control systems have been conceptualized and a model of the comer-cube resonator is being built and tested. Finally, threedimensional simulations of the FEL have been carried out which show that the laser should exceed its minimum design goals for average power. 


\section{DISCLAIMER}

Portions of this document may be illegible in electronic image products. Images are produced from the best available original document. 


\section{DISCLAIMER}

This report was prepared as an account of work sponsored by an agency of the United States Government. Neither the United States Government nor any agency thereof, nor any of their employees, makes any warranty, express or implied, or assumes any legal liability or responsibility for the accuracy, completeness, or usefulness of any information, apparatus, product, or process disclosed, or represents that its use would not infringe privately owned rights. Reference herein to any specific commercial product, process, or service by trade name, trademark, manufacturer, or otherwise does not necessarily constitute or imply its endorsement, recommendation, or favoring by the United States Government or any agency thereof. The views and opinions of authors expressed herein do not necessarily state or reflect those of the United States Government or any agency thereof. 


\section{Introduction}

At the Sixteenth International FEL Conference, we described the design of a UV free-electron laser (FEL) featuring a superconducting accelerator and energy recovery [1]. This design would test the technologies necessary for scale-up to a $100-\mathrm{kW}$-class free-electron laser for industrial processing. The design consists of a $10 \mathrm{MV}$, high-brightness electron injector, a two-pass, 190 $\mathrm{MeV}$ accelerator, and a wiggler within a 64 meter optical resonator. The exhaust electron beam from the FEL is decelerated for energy recovery and dumped at $10 \mathrm{MeV}$.

We have carried out a design optimization procedure to streamline the accelerator and FEL design, reduce the overall project risk, and resolve several problematic issues. The risk was reduced by quantifying the performance degradation from the elements that have the most technical risk and spreading the performance sensitivity evenly among the critical technologies. We have identified the critical issues in the design of a UVFEL driven by an energy recovery linac:

- One must achieve high brightness with a continuously-pulsed, high-charge electron beam.

- Emittance growth in such a machine must be carefully controlled.

- An accelerator with a net synchrotron tune of one half is inherently unstable and must have active feedback control [2].

- Beam losses in a high power machine must be kept very small both for machine protection and to ensure RF stability.

- Mirror coatings in the deep UV are lossy. This leads to problems with poor output coupling and mirror distortion.

We also considered other parameters which might affect FEL performance. In all other cases, either the FEL performance was insensitive to the parameter or the parameter was easily achieved.

Several key parameters were changed from the original design. A design optimization versus electron bunch charge found that a charge of only $135 \mathrm{pC}$ was nearly optimum for our baseline 
design. The repetition rate of the injector was therefore changed to $37.425 \mathrm{MHz}$. We found that bunching at $200 \mathrm{MeV}$ can produce quite short bunches. We now assume a bunch length of only $0.5 \mathrm{ps}$ with a peak current of $270 \mathrm{~A}$. This raises the normalized transverse emittance but we still estimate that the emittance at the FEL will be less than $11 \pi \mathrm{mm}$-mrad. It is assumed that the wiggler will be the same as those now being used in the Advanced Photon Source at Argonne National Laboratory. These have a $3.3 \mathrm{~cm}$ wiggler period and 72 periods.

\section{Injector}

We have enhanced the injector model to include accurate three-dimensional fields for the superconducting cavities and accurate two dimensional models for the solenoids and the buncher cavity [3]. The space charge algorithm was improved and benchmarked against ISIS [4]. The new simulations indicate that a $135-\mathrm{pC}$ bunch can be accelerated to $10 \mathrm{MeV}$ and injected into the accelerator while maintaining normalized transverse and longitudinal emittances of less than $5 \pi$ mm-mrad and $20 \pi \mathrm{keV}$-deg.

An injector test stand is under construction at CEBAF to test the injector design. A shielded enclosure has been modified to accept the injector. Rooms to house the control system, the photocathode drive laser, and the high voltage power supply have been constructed. The vacuum chambers, $\mathrm{SF}_{6}$ tank, and the support structure for the gun are complete. High voltage electrodes are almost complete and assembly has begun on the gun. The cryounit and RF systems are scheduled to be completed by the end of this year. Prototypes of high power windows and high power couplers have been fabricated and successfully tested.

\section{Lattice Design}

We have modified the previous lattice design to improve the injection and extraction of the 10 $\mathrm{MeV}$ beams and to decrease the footprint of the accelerator [5]. The new design allows the energy of the accelerator to be changed independently from the injector energy and allows operation at half 
energy with only one accelerating pass for infrared operation. A bypass has been designed to accommodate a 5.4 meter optical klystron for infrared operation.

\section{Resonator modeling}

To handle the high average power density in the UV demo with reasonable mode quality we plan to use a retro-reflecting, re-imaged, ring resonator (or $\mathrm{R} 5$ resonator) [6]. The $\mathrm{R} 5$ resonator is a negative-branch, unstable resonator with scraper output coupling. This design has the advantage of using all reflective surfaces. The lowest order mode of this resonator has a top hat profile at the scraper and an Airy profile at the wiggler. Simulations both with a Beer's law gain profile and FELEX [7] show that the presence of the wiggler bore and a gain medium rounds the top hat profile and reduces the output coupling for a given magnification. The gain of this mode is less than that of a Gaussian mode. Gaussian mode simulations at $200 \mathrm{~nm}$ predict a gain of $125 \%$ while FELEX predicts approximately $100 \%$. The Gaussian simulation predicts a peak power output of $130 \mathrm{MW}$ while the FELEX simulation predicts a power output of $70 \mathrm{MW}$. Given a duty cycle of $1.8 \times 10^{-5}$ the average power is then greater than $1300 \mathrm{~W}$. An interesting feature of the FELEX simulations is that the power output is insensitive to the electron beam focussing, contrary to expectations.

A serious disadvantage of the R5 resonator design is the need for six reflections in each round trip. Though mirrors are quite adequate for wavelengths longer than $250 \mathrm{~nm}$, the reflectivity of mirrors in the deep UV is typically $98-99 \%$ for normal incidence and is usually only about $92 \%$ for a $54^{\circ} \mathrm{p}$-plane reflection. We are working with the University of Arizona Optical Science Center to develop deep UV optics with higher p-plane reflectivity. If this does not work, we will use a roof-top reflector with all s-plane reflections, which is quite adequate for the kilowatt demonstrator but is not scalable to the $100 \mathrm{~kW}$ device.

To test such issues as depolarization, net reflectivity, length control, and figure control, we are building a full size mockup of the R5 resonator using mirrors with reflective coatings at 630 
$\mathrm{nm}$. This will allow us to test out the basic design of the resonator before building the final device.

\section{Energy Stability}

Recirculating, energy-recovering accelerators exhibit instabilities which arise from fluctuations of the cavity fields. Energy changes can cause beam loss on apertures, or, when coupled to $\mathrm{M}_{56}$, phase oscillations. Both effects change the beam induced voltage in the cavities and can lead to unstable variations of the accelerating field. Stability analysis for small perturbations from equilibrium has been performed [2] and the threshold current for the CEBAF FEL has been determined to be 300 microAmps. The model has been extended to include amplitude and phase feedback, with the transfer function of the feedback presently modeled as a low-pass filter. It was found that, for small variations, modest gain frequencies, well within CEBAF's RF control system capability, are required to stabilize the system.

\section{Conclusions}

Optimization studies for the UV demo design have produced a robust design that meets the minimum design requirements of the users. Several potential problems have been extensively studied and found soluble. We are continuing the study of the emittance growth of short electron beams, which might be enhanced by coherent synchrotron emission, and overall phase and gradient stability of energy recovered systems. The lattice is also being optimized to reduce component count and cost.

Acknowledgments: This work was supported by the Virginia Center for Innovative Technology and DOE Contract \# DE-AC05-84ER40150. 


\section{References}

1. G.R. Neil, S.V. Benson, H. F. Dylla, and H. Liu, "CEBAF UV/IR subsystem testing and validation program", Proc. of the 1994 FEL conference. NIM

2. L. Merminga, J.J.Bisognano, J.R.Delayen, "Energy Stability in Recirculating, Energy-recovering Linacs," these proceedings.

3. H. Liu et al.,"Design of a high charge CW photocathode injector test stand at CEBAF", Proc. 1995 Particle Accelerator Conf. Dallas TX (1995).

4. H. Liu, CEBAF TN\# 94-040.

5. D. Neuffer et al., "Beam Transport For An SRF Recirculating-Linac FEL", These proceedings.

6. Chun-Ching Shih and Su-Miau Shih, Nucl. Inst and Meth. A304 (1991) 788.

7. B. D. McVey, Nucl. Inst. and Meth. A250 , (1986) 449. J. C. Goldstein et. al., Proc. SPIE 1045, "Modeling and Simulation of Laser Systems", ed. B. L. Bullock, p. 28. 
This report has been reproduced from the best available copy.

Available to DOE and DOE contractors from the Office of Scientific and Technical Information, P.O. Box 62, Oak Ridge, TN 37831; prices available from (615)576-8401, FTS 626-8401.

Available to the public from the National Technical Information Service, U.S. Department of Commerce, 5285 Port Royal Rd., Springfield, VA 22161.

Price: Printed copy $\mathrm{AO} 2$ Microfiche 101 